\title{
Prognostic significance of the pattern visual evoked potential in ocular hypertension
}

\author{
Lindsay Charles Bray, Keith William Mitchell, John William Howe
}

\begin{abstract}
This paper reports a prospective study on 49 ocular hypertensive patients to evaluate the prognostic significance of transient abnormalities in the pattern visual evoked potential (VEP) in the development of glaucoma. Seven of 24 patients with VEP abnormalities at diagnosis of ocular hypertension developed glaucomatous field defects in the follow-up period as compared with none of 25 patients with normal VEPs at diagnosis. We conclude that appropriately designed pattern VEP testing is a valuable complement to careful (preferably computerised, static) perimetry. In addition, our findings support the contention that, in glaucomatous disease of the optic nerve, rudimentary pattern processing mechanisms that is ' $Y$ '-type units of the magnocellular pathways - may be affected earlier than luminance processing mechanisms.
\end{abstract}

The diagnosis of chronic simple glaucoma (CSG) in routine clinical practice is made when a raised intraocular pressure (IOP) of $>21 \mathrm{mmHg}$ is accompanied by characteristic optic nerve head cupping and visual field defects. Ocular hypertension $(\mathrm{OH})$, however, presents us with more complicated problems in terms of both definition and management. In theory, $\mathrm{OH}$ is a benign elevation of IOP, that is, one that does not cause damage to retinal ganglion cells. In clinical practice, however, $\mathrm{OH}$ is defined as an elevation of IOP in the absence of detectable visual field loss. Clearly these two may not be the same, as they depend very much on the field technique used to ascertain early CSG. The difference between these definitions was demonstrated by Quigley and colleagues in pathological studies of optic nerves and retinae of $\mathrm{OH}$ and CSG sufferers. He showed that, by the time glaucomatous field loss was detected by Goldmann perimetry, up to $40 \%$ of optic nerve fibres were lost. ${ }^{1}$ In a recent paper Quigley correlated retinal ganglion cell loss (demonstrated histologically) with visual field loss detected by the Octopus and Humphrey computerised static perimeters. He showed that a $20-40 \%$ reduction in ganglion cells corresponded to a loss of sensitivity of 5-10 dB. ${ }^{2}$

Although raised IOP is intimately associated

University Department of Ophthalmology, Pavilion 2, Royal Victoria Infirmary, Newcastle upon Tyne NE1 4LP LCBray

K W Mitchell

J W Howe

Correspondence to:

Dr K W Mitchell.

Accepted for publication 30 July 1990 with glaucoma, the two are not synonymous. Prospective studies of $\mathrm{OH}$ have suggested that less than $30-35 \%$ of patients will eventually develop CSG and it is impossible to predict which of them it will be. ${ }^{3-5}$ Consequently, clinical management is problematical. On the one hand benign ocular hypertensives could be subject to unnecessary and potentially hazardous treatment, while on the other, withholding treatment from those with incipient glaucoma could result in accelerated field loss. Many clinicians, therefore, attempt a compromise and treat only those patients with an IOP of $>30 \mathrm{mmHg}$ in whom the probability of CSG is higher.

A number of alternative approaches have been advocated in an attempt to improve both detection and monitoring of $\mathrm{OH}$ and CSG. Stereoscopic optic $\operatorname{disc}^{6}$ and nerve fibre layer photography ${ }^{78}$ have been advocated as more sensitive indicators of damage as well as other tests of visual function, including colour vision, ${ }^{910}$ flicker perimetry, ${ }^{11}$ contrast sensitivity, ${ }^{1213}$ and recording of the visual evoked potential (VEP) ${ }^{14-17}$ and the pattern electroretinogram (PERG). ${ }^{18-24}$ The VEP to pattern stimulation has been shown to demonstrate not only attenuation in CSG, but delay of the P100 component of the so-called 'transient' VEP and phase shifting of the 'steady state' VEP..$^{1516}$ Interestingly, significantly delayed latencies have also been observed in $25-50 \%$ of $\mathrm{OH}$ eyes. ${ }^{161725}$ Earlier work in this department demonstrated a poor sensitivity of the VEP to detection of CSG in patients with superior visual field defects due to the dominance of the inferior hemifield signal to the full field VEP response. ${ }^{25}$ Consequently an alternative technique was devised in which VEPs to superior and inferior hemifields were elicited separately, and the overall illumination of the central and peripheral retina was more carefully controlled. In this large comparative study these modifications were found to improve the detection rate of CSG. In addition abnormalities were reported in nearly $50 \%$ of $\mathrm{OH}$ patients. It was suggested that such a large figure may partly be explained by the relatively poor sensitivity of the Goldmann perimeter in detecting early field defects, an observation confirmed by a number of comparative studies using computerised static perimetry. ${ }^{26} 27$

The purpose of this study, therefore, was to examine the transient pattern VEP in a group of ocular hypertensive patients who were then followed up prospectively to see if the presence of VEP abnormalities was of any prognostic value in relation to the development of glaucoma.

\section{Material and methods}

SUBJECTS AND PATIENTS
Forty-nine patients diagnosed as having $\mathrm{OH}$ were selected from the glaucoma clinic at the Royal Victoria Infirmary between late 1984 and early 1989. All patients were subjected, at diagnosis, to full ophthalmological examination including Snellen visual acuity, applanation tonometry, gonioscopy, and funduscopy. Initial visual fields in 25 patients were recorded by the 
Goldmann perimeter (targets $14_{\mathrm{e}}$ or $\mathrm{I} 2_{\mathrm{e}}$ ) and in the other 24 by the Octopus 2000R automated perimetry (program 34 ).

A diagnosis of ocular hypertension was made when the following criteria were fulfilled: (1) 31 $\mathrm{mmHg}>\mathrm{IOP}>21 \mathrm{mmHg}$; (2) a healthy optic disc (cup/disc ratio $<0.6$ with ophthalmoscopically normal neuroretinal rim and nerve fibre layer); (3) a full visual field.

Patients were excluded from the study if their visual acuity was $<6 / 9$, either due to media opacity or concomitant choroidoretinal pathology. In addition patients with miotic pupils (either due to senile miosis or drugs) were excluded from the study, since miosis is known to influence the VEP. ${ }^{15}$

Repeat visual field and electrophysiological testing was performed in the latter part of 1989. All 49 patients had Octopus field testing, and in addition those initially diagnosed by kinetic perimetry were reassessd by this method. Average follow-up period was $3 \cdot 2$ years $(0 \cdot 9-5 \cdot 8 \mathrm{yr})$. In addition 26 age matched, normal subjects were tested to establish VEP control ranges.

\section{ELECTROPHYSIOLOGY}

The checkerboard was produced by a video pattern generator (Medelec) on a high quality TV monitor (Barco). ${ }^{28}$ Luminance (L) modulation of the pattern was selected to give the pattern reversal mode of stimulation of a rate of 2 reversals per second. Check subtense was selected to be $100^{\prime}$, pattern contrast (defined as $\mathrm{L}_{\max }$ $\left.\left.\mathrm{L}_{\min }\right) /\left(\mathrm{L}_{\max }+\mathrm{L}_{\min }\right)\right)$ set at $40 \%$ and patientmonitor distance adjusted so that the stimulus field subtended $33^{\circ} \times 26^{\circ}$. The monitor was surrounded by a light adapting screen which was adjusted to the same luminance as the space average luminance of the TV monitor, namely,

Control Subject (Age: 61)
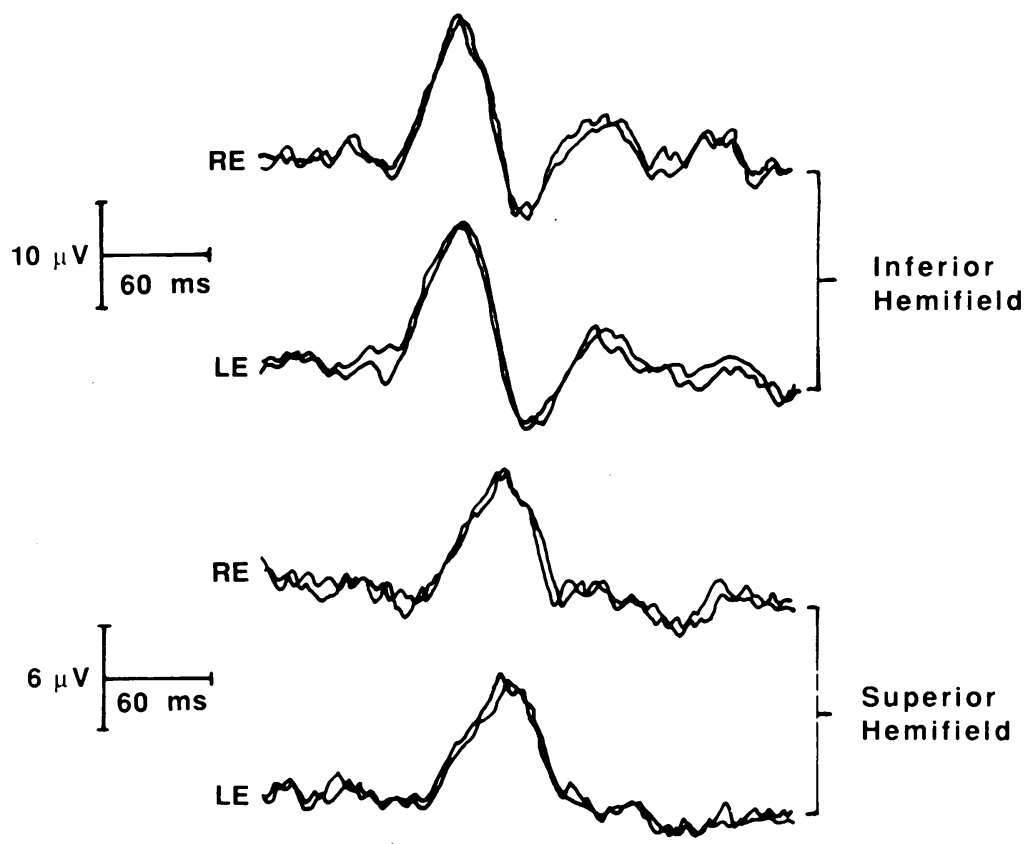

Figure 1 Pattern VEPs from a control subject. Upper traces to inferior hemifield stimulation, lower traces to superior hemified stimulation.
$10.4 \mathrm{Cd} . \mathrm{m}^{-2}$. The screen measured $1.9 \mathrm{~m} \times 1.9 \mathrm{~m}$ and subtended $120^{\circ} \times 120^{\circ}$ at the retina.

Silver/silver-chloride disc electrodes were attached to the scalp with collodion in the following positions as defined by Jasper ${ }^{29}$ : active-' $0_{z}$ '; reference-' $C_{z}$ '; earth-' $P_{z}$ '. Electrode impedences were adjusted to be $<2 \mathrm{kohm}$ in both active and reference leads. For inferior hemifield stimulation (IHS) a light emitting diode (LED) fixation spot was attached to the top centre of the monitor screen and for superior hemified stimulation (SHS) it was attached to the bottom centre, thus ensuring appropriate positioning of the subject's fixation in relation to the stimulus. Depending upon the size of the response, either 64 or 128 epochs of $300 \mathrm{~ms}$ duration was amplified, averaged, and stored. Two averages were obtained to check for consistency, and quantitative analysis was performed on the average of the two. Monocular stimulation was performed throughout the study, the nonstimulated eye being occluded with a patch. Pupil diameter was measured at the conclusion of the test.

The latency of the P100 component was measured, as was peak-peak amplitude between the $\mathrm{P} 100$ and N150 peaks.

STATISTICAL TREATMENT OF RESULTS

In the establishment of control ranges for absolute values of VEP measures data from one eye were selected from each individual, at random, as data from both eyes do not constitute truly random variables. ${ }^{30}$ The level of statistical significance throughout all experimentation was selected to be at the $1 \%$ level $(p<0.01)$. The effect of pathology was assumed to produce excursions from normality in one direction only - for example, latency increase, amplitude reduction - so that single-tailed Student's $t$ test analysis was applied to all data.

\section{Results}

Representative VEPs from a control subject are shown in Fig 1, the responses to IHS being illustrated in the top half of the figure and those to SHS in the lower half. The characteristic P100 component and its succeeding component, the $\mathrm{N} 150$, are clearly evident in all responses. A striking feature of the data in relation to the two stimulating modes is the longer component latency to SHS as compared with IHS. This feature is associated with the differing characteristics of the retinocortical pathways subserving the inferior and superior hemiretinae. ${ }^{3132}$ For the control group as a whole, normal ranges for

Table 1 Normal ranges for VEP parameters

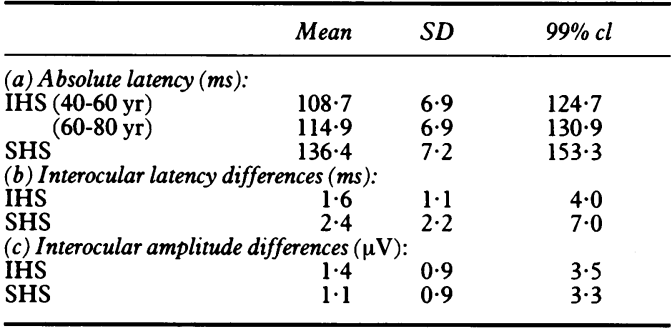


Glaucoma Patient (Age: 70)

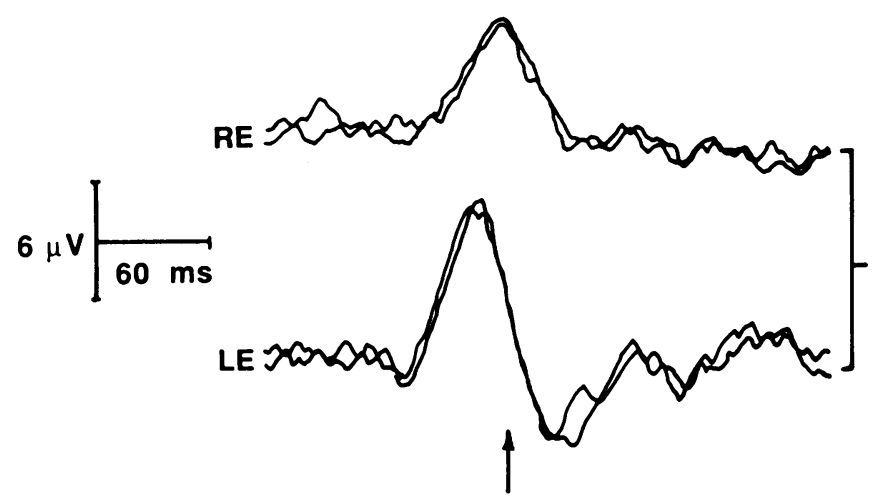

Inferior Hemifield

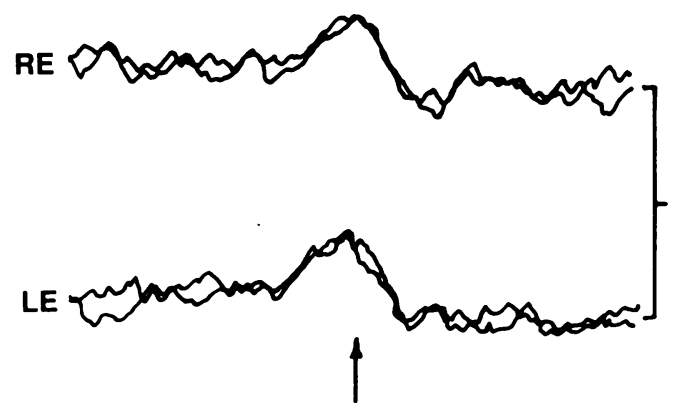

Superior Hemifield stimulation, lower traces to superior hemifield stimulation.

absolute P100 latency and interocular differences in both latency and amplitude were established (Table 1a-c). No sex differences were found, but there was a trend towards increasing latency with age for IHS. Consequently, absolute latency data were separated into two age bands. From these results $99 \%$ confidence limits (cl) were determined (Table 1). Absolute values of amplitude showed considerable interindividual variation, which resulted in a large standard deviation. Lower limits were therefore (nonsensically) below zero, thus precluding the clinical utility of this measure.

VEPs from a glaucoma patient are shown in Fig 2 (as an aid in comparing these data with those of normal persons, arrow markers indicate the upper $99 \% \mathrm{cl}$ of the control ranges). It can be seen that to IHS there is a marked interocular difference in latency, the right eye responses having significantly longer latency than those from the left eye, even though both are within the normal range. There is also some attenuation of the former response as compared with the latter. The recordings to SHS do not show any differential effects but do have latencies towards the top end of the normal range. In relation to the patient group as a whole they, at initial presentation, showed latency abnormalities (absolute and/or interocular differences) in 16 of 49 patients $(32 \cdot 7 \%)$ (compared with two of 26 controls $(7 \cdot 7 \%))$. All 16 had significant interocular differences in latency (nine had abnormalities to IHS and 11 had abnormalities to SHS) and two revealed an absolute latency delay. In relation to interocular amplitude abnormalities, 14 of the 49 $(28 \cdot 6 \%)$ were significant - again, this compared with two of 26 controls $(7 \cdot 7 \%)$. In addition, one patient had an unusual VEP waveform, and
Table 2 Diagnostic outcome at follow-up in relation to initial VEP

\begin{tabular}{llll}
\hline Initial VEP & $O H$ & CSG & Reverted \\
\hline Normal & 23 & 0 & 2 \\
Abnormal & 16 & 7 & 1 \\
\hline
\end{tabular}

Table 3 Comparison of initial and follow-up VEP for $\mathrm{OH}$ patients

\begin{tabular}{llc}
\hline & \multicolumn{2}{l}{ Follow up VEP } \\
\cline { 2 - 3 } Initial VEP & Normal & Abnormal \\
\hline Normal & 22 & 3 \\
Abnormal & 7 & 17
\end{tabular}

although detailed analysis of it was not feasible it was considered to be abnormal and was included in all subsequent analysis as such. Overall, 24 of 49 patients $(49.0 \%)$ showed some sort of abnormality at initial diagnosis. Of these, 12 were initially assessed by Goldmann field and 12 by Octopus.

Reassessment of the $\mathrm{OH}$ group at follow-up resulted in a reassignment of diagnosis as shown in Table 2. The most significant feature of these data is that all seven who were subsequently confirmed as early CSG had an abnormal VEP on initial assessment. It should be noted that five of these were initially assessed by Goldmann perimetry and field defects were subsequently demonstrated by both this method and Octopus. The other two were assessed by the latter method alone. The additional 16 with abnormalities were, on reassessment, still regarded as $\mathrm{OH}$. It is also interesting, and somewhat reassuring, to note that, of the 23 who had normal VEPs, none had developed signs of CSG by the end of the follow-up period. The 'reverted' column refers to those patients whose subsequent IOP readings were consistently found to be normal. A comparison between results of the follow-up VEPs and the initial recordings is shown in Table 3. The 17 patients who had consistently abnormal VEPs included the seven who developed glaucomatous damage. Of the seven whose results returned to normal four had an increase in latency in their fellow eye, resulting in a loss of the previously reported interocular difference. The remaining three had no such explanation for the return of their VEP to 'normality' and included the single patient from this group who 'reverted'. Of the 25 patients who initially had normal VEPs 22 remained normal, two developed interocular differences in latency, and one an interocular difference in amplitude. The VEPs

Table 4 Comparison of mean intertest changes in VEP latency

\begin{tabular}{llll}
\hline & $\begin{array}{l}\text { Intertest } \\
\text { mean }\end{array}$ & $S D$ & $\begin{array}{l}\text { Significance } \\
(d f)^{\star}\end{array}$ \\
\hline (a) IHS & & & \\
OH (VEP normal) & -0.91 & $4 \cdot 17$ & \\
OH (VEP abnormal) & $+1 \cdot 19$ & 4.72 & $\mathrm{NS}(37)$ \\
CSG & +4.33 & 7.74 & $\mathrm{p}=0.015(27)$ \\
(b) SHS & & & \\
OH (VEP normal) & -1.00 & 5.68 & \\
OH (VEP aonormal) & +3.38 & 4.73 & $\mathrm{p}=0.008(37)$ \\
CSG & +6.83 & 8.77 & $\mathrm{p}=0.006(27)$ \\
\hline
\end{tabular}

$\star$ Degrees of freedom. 
of the two patients who 'reverted' were normal on retesting.

We also compared the mean intertest changes in VEP parameters of those ocular hypertensives who initially had normal VEPs respectively with those who had abnormal VEPs but remained $\mathrm{OH}$, and those who developed CSG (Table 4). In relation to the former some difference was demonstrated in latency, but this was significant for the SHS mode alone (Table 4b). As to the latter, notwithstanding the small number in the CSG group (seven), significance was observed for both stimulation modes, at the significance level shown (Table 4a, b). Mean intertest amplitude did not show any changes in either group.

\section{Discussion}

Though the earliest studies of the VEP in $\mathrm{OH}$ failed to reveal any abnormalities, ${ }^{14}{ }^{15}$ in recent years there have been a number of reports showing changes. ${ }^{16} 1725$ In addition there has been much enthusiasm concerning the potential application of the PERG in both ocular hypertension and early CSG, ${ }^{18-24}$ where the main finding has been attenuation of the response. Consequently, its application in the diagnosis and management of these conditions has been advocated. However, it is well understood in visual electrophysiology that absolute amplitude is a 'soft' quantity, whereas latency, or more correctly in this particular context implicit time, is a 'hard' quantity, - that is, amplitude measurements demonstrate large interindividual variability, whereas latency/implicit time measurements show small interindividual variability. Therefore, as PERG implicit time has shown little or no change in glaucoma, ${ }^{20}$ its clinical utility is vitiated by the significant overlap of amplitude distributions of control and $\mathrm{OH} / \mathrm{CSG}$ populations. ${ }^{21}{ }^{22}$ An attempt has been made to overcome this problem by adopting ratiometric techniques in relation to the measurement of PERG componentry, ${ }^{24}$ and with some success. However, there are still problems, as measurement of amplitude has to be made with respect to a stable 'baseline', a condition notoriously difficult to achieve in the routine clinical setting.

With regard to the transient pattern VEP, Towle's group ${ }^{16}$ demonstrated significantly delayed latencies in $23 \%$ of $\mathrm{OH}$ patients, and subsequent studies using refined stimulation techniques have observed up to $47 \%$ of such patients with abnormalities. ${ }^{1725}$ The incidence of $49 \%$ in this present study generally concurs with these previous findings. A recent study using the flash VEP ${ }^{33}$ has attempted to advocate the use of this method clinically, but it has long been known in electrophysiological research that such potentials are limited by wide variability of amplitude within the normal population and large interindividual variation in form. ${ }^{34} \mathrm{It}$ is also impossible adequately to control retinal adaptation levels and exclude problems due to stray and scattered light. Consequently, the predictable finding of significant overlap in P1 amplitudes of control and pathological populations in glaucoma ${ }^{33}$ does, we believe, preclude its use for this purpose.
To our knowledge this present report is the first published follow-up study undertaken to determine the prognostic significance of electrophysiological abnormalities in $\mathrm{OH}$. The most striking feature of our results is that all seven patients who eventually developed glaucomatous field defects had VEP abnormalities at initial diagnosis of ocular hypertension. As a group they also showed increases in VEP latency at follow-up, thus demonstrating a deterioration of retinal ganglion cell function due to incipient glaucomatous damage. It must be conceded, however, that had the five who were initially classified by kinetic perimetry been subjected to more sensitive computerised static perimetry, their initial diagnosis might have been different. In relation to the 16 patients with VEP abnormalities at initial examination who have yet to develop field defects, we believe that they must be followed up carefully to determine whether they are in the early stages of glaucoma or whether they are false positives due to lack of specificity of the VEP. However, set against the latter possibility is the fact that, in common with the group who developed signs of glaucoma, they showed a significant increase in mean latency (albeit to SHS alone), strengthening the contention that they do indeed have incipient glaucoma. Thus we consider it is justifiable to assert that $\mathrm{OH}$ patients with VEP abnormalities at initial presentation are at higher risk of developing glaucoma.

With respect to the $\mathrm{OH}$ group with normal VEPs at diagnosis, none of them so far have developed field defects, and intertest comparisons have revealed marked stability of VEP parameters. Twenty-two of the original 25 patients in this group have maintained normality on repeat testing and therefore we consider can be regarded as at low risk of developing glaucoma. Three, however, have developed VEP abnormalities and obviously must be treated with more caution. There are problems of course, in giving the correct weight to measurements of interocular differences. These may be absent in symmetrical glaucoma, leading, falsely, to the reporting of normality. Intertest comparisons are of more value in this instance, as they may reveal deterioration of VEP parameters that one would fail to detect when comparing a single VEP with the normal range. This was illustrated in our study group, six of the $16 \mathrm{OH}$ patients with VEP abnormalities at diagnosis were reported as having normal VEPs on follow-up. Intertest comparisons, however, revealed an increase in latency in the fellow eye of four of them, and therefore there is the distinct suspicion that they could be abnormal.

As no patient in the study had any concomitant neurophysiological or ophthalmological disorders, or confounding factors due to optical errors or medial opacities which could have compromised the data, we are confident in ascribing the effects to early glaucomatous processes. The result of such damage is, we would argue, consistent with the theory that units with large receptive field size and high contrast sensitivity - the ' $Y$ '-type cells of the magnocellular pathways - are damaged first in glaucoma..$^{35}$ This is not an unreasonable 
suggestion, as our VEP stimulation technique, namely, field size/location, check size/contrast, and surround illumination, generally matches the characteristics and retinal location of such units. We would thus argue that such factors are of considerable import in the design of VEP experimentation to maximise clinical effectiveness.

The transient pattern VEP is a straightforward investigation which takes 10-15 minutes in total to perform and requires the patient to fixate for only about 30-60 seconds at any one time. It thus requires less co-operation than conventional kinetic or computerised static perimetry and therefore has distinct advantages with regard to that group of patients who have difficulty in performing a field investigation. However, our current understanding of the effects of early glaucomatous pathology on visual function, coupled to the qualified conclusions of this modest follow-up study, do not allow us to advocate VEP methods as a substitute for careful static perimetry. What it does suggest is that the two techniques are complementary, the former giving us objective data on, primarily, pattern processing mechanisms, whereas the latter elicits subjective data on primarily luminance processing mechanisms. There is mounting evidence to support the contention that pattern mechanisms are affected in advance of luminance mechanisms in early glaucoma, ${ }^{37}$ and the findings of this study are in concordance with these. Much work still needs to be done, however to expand our knowledge of such processes further. In addition more extended, prospective studies on larger patient cohorts are required before we can confidently support the pattern VEP as an earlier indicator of incipient glaucoma.

The authors express their sincere thanks to Karen Copeland, chief medical physics technician, who with skill and alacrity elicited most of the electrophysiological and visual field data in this study.

1 Quigley HA, Addicks EM, Green WR. Optic nerve damage in human glaucoma III. Quantitative correlation of nerve fiber loss and visual field defect in glaucoma, ischemic neuropathy, disc edema, and toxic neuropathy. Arch Ophthalmol 1982; 100: 135-46.

2 Quigley HA, Dunkelberger GR, Green WR. Retinal ganglion cell atrophy correlated with automated perimetry in human eyes with glaucoma. Am f Ophthalmol 1989; 107: 453-64.

3 Perkins ES. The Bedford glaucoma survey. I. Long-term follow-up of borderline cases. $\mathrm{Br} \mathcal{F}$ Ophthalmol 1973; 57: 179-85.

4 Kahn HA, Leibowitz HM, Ganley JP, et al. The Framingham Eye Study. I: Outline and major prevalence findings. $A m \mathcal{J}$ Epidemiol 1977; 106: 17-23.

5 Aasved H, Hovding G. The Bergen Glaucoma Study: diagnostic criteria, epidemiology, prognostic factors and indicators for treatment. Chibret International d'Opthalmologie 1987; 5: 4-19.

6 Johnson CA, Keltner JL, Krohn MA, Portney GL. Photogrammetry of the optic disc in glaucoma and ocular hypergrammetry of the optic disc in glaucoma and ocular hyperOphthalmol Vis Sci 1979; 18: 1252-63.

7 Airaksinen PJ, Nieminen H. Retinal nerve fiber layer photography in glaucoma. Ophthalmology 1985; 92: 877-9.

8 Takamoto T, Schwarz B. Photogramme nerve fiber layer thickness. Ophthalmology 1989; 96: 1315-9.

9 Fishman GA, Krill AE, Fishman M. Acquired color defects in patients with open angle glaucoma and ocular hypertension. Mod Probl Ophthalmol 1974; 13: 335-8.
10 Gunduz K, Arden GB, Perry S, Weinstein GW, Hitchings RA Colour vision defects in ocular hypertension and glaucoma. Quantification with a computer driven color television system. Arch Ophthalmol 1988; 106: 929-35.

11 Campbell CJ, Rittler M. The diagnostic value of flicker perimetry in chronic simple glaucoma. Ophthalmology 1959; 63: 89-98.

12 Arden GB, Jacobson JJ. A simple grating test of contrast sensitivity: preliminary results indicate value in screening for glaucoma. Invest Ophthalmol Vis Sci 1978; 17: 23-32.

13 Hitchings RA, Powell DJ, Arden GB, Carter RM. Contrast sensitivity gratings in glaucoma family screening. $\mathrm{Br} \mathcal{F}$ Ophthalmol 1981; 61: 107-13.

14 Cappin JM, Nissim S. Visual evoked responses in the assessment of field defects in glaucoma. Arch Ophthalmol 1975; 93: 9-18.

15 Sokol S, Domar A, Moskovitz A, Schwarz B. Pattern evoked potential latency and contrast sensitivity in glaucoma and ocular hypertension Doc Ophthalmol Proc Ser 1981; 27: 79_ 86.

16 Towle VL, Moskovitz A, Sokol S. Schwarz B. The visual evoked potential in glaucoma and ocular hypertension. Effects of check size, field size and stimulation rate. Invest Ophthalmol Vis Sci 1983; 24: 175-83.

17 Howe JW, Mitchell KW. Visual evoked cortical potential to paracentral retinal stimulation in chronic glaucoma, ocular hypertension and an age-matched group of normals. Doc Ophthalmol 1985; 63: 37-44.

18 Fiorentini A, Maffei L, Pirchio M, Porciatti V, Spinelli D. Pattern ERG in patients with unilateral alterations in Pattern ERG in patients with unilateral alterations
ganglion cells. Doc Ophthalmol Proc Ser 1981; 31: 131-3.

19 Wanger $P$, Persson HE. Pattern reversal electroretinograms in unilateral glaucoma. Invest Ophthalmol Vis Sci 1983; 24: 749-53.

20 Howe JW, Mitchell KW. Simultaneous recording of pattern electroretinogram and visual evoked cortical potential in a group of patients with chronic glaucoma. Doc Ophthalmol Proc Ser 1984; 40: 101-8.

21 Van Lith GHM, Ringens P, de Heer LJ. Pattern electroretinogram and glaucoma. Dev Ophthalmol 1984; 9: 133-9.

22 Wanger $P$, Persson HE. Pattern reversal electroretinograms from normotensive, hypertensive, and glaucomatous eyes. Ophthalmologica 1987; 195: 205-8.

23 Weinstein GW, Arden GB, Hitchings RA, Ryan S. Calthorpe CM, Odom JV. The pattern ERG in ocular hypertension and CM, Odom JV. The pattern ERG in ocular hyper

24 Odom JV, Feghali JG, Jin J, Weinstein GW. Visual function deficits in glaucoma: electroretinogram pattern and luminance nonlinearities. Arch Ophthalmol 1990; 108: 2227.

25 Mitchell KW. The visual evoked potential in the differential diagnosis of ocular hypertension and chronic simple glaucoma. Ph D thesis. University of Newcastle upon Tyne, 1987.

26 Sommer A, Enger C, Witt K. Screening for glaucomatous visual field loss with automated threshold perimetry. $A m \mathcal{F}$ Ophthalmol 1987; 102: 681-4.

27 Krieglstein GK, Screms W, Leydhecker W. Detectability of early glaucomatous field defects. A controlled comparison of Goldmann versus Octopus perimetry. Doc Ophthalmol Proc Goldmann versus Octo

28 Arden GB, Faulkner DJ, Mair C. A versatile television pattern generator for visual evoked potentials. In: Desmedt JE, ed. Visual evoked potentials in man: new developments. Oxford: Clarendon Press, 1977.

29 Jasper HH. Report of the committee on methods of clinical examination in electroencephalography. Electroencephalogr Clin Neurophysiol 1958; 10: 370-5.

30 Ederer F. Refereeing clinical research papers for statistical content. (Editorial.) Am f Ophthalmol 1985; 100: 735-7.

31 Lehmann D, Skrandies W. Multichannel evoked potential fields show different properties of human upper and lower hemiretina systems. Exp Brain Res 1979; 35: 151-9.

32 Barber C, Galloway NR. Pattern evoked potentials as indicators of functional visual field asymmetries. Doc Ophthalmol Proc Ser 1981; 27: 229-37.

33 Watts MT, Good PA, O'Neill EC. The flash stimulated VEP in the diagnosis of glaucoma. Eye 1989; 3: 732-7.

34 Halliday AM. The visual evoked potential in healthy subjects. In: Halliday, AM, ed. Evoked potentials in clinical testing. London, Edinburgh: Churchill Livingstone, 1982: 71-120.

35 Marx MS, Podos SM, Bodis-Wollner I, Lee PY, Wang RF, Severin C. Signs of early damage in glaucomatous monkey eyes: low spatial frequency losses in the pattern ERG and VEP. Exp Eye Res 1988; 46: 173-84.

36 Quigley HA, Hendrickson A. Chronic experimental glaucoma in primates: blood flow study with iodantipyrine and pattern of selective ganglion cell loss. Invest Ophthalmol Vis Sci 1984; 25 (suppl): 225 .

37 Neima D, Le Blanc R, Regan D. Visual field defects in ocular hypertension and glaucoma. Arch Ophthalmol 1984; 102: 1042-5. 